INTERNATIONAL JOURNAL OF MULTIDISCIPLINARY RESEARCH AND ANALYSis

ISSN(print): 2643-9840, ISSN(online): 2643-9875

Volume 05 Issue 02 February 2022

DOI: 10.47191/ijmra/v5-i2-29, Impact Factor: 6.072

Page No. $440-445$

\title{
The Comparison of Highschool Students' Happiness between On- site and Online Learning and its Correlation with Motivation to Learn
}

\author{
Fukue Suntarat $^{1}$, Porwarat Chawanid ${ }^{2}$, Napon Kanoksilp ${ }^{3}$, Napatrapee Siramungklanon ${ }^{4}$ \\ ${ }^{1}$ International School Bangkok, Bangkok, Thailand \\ ${ }^{2}$ Srinakharinwirot university Prasarnmit demonstration school (secondary), Bangkok, Thailand \\ ${ }^{3}$ Patumwan Demonstration School, Srinakharinwirot University, Bangkok, Thailand \\ ${ }^{4}$ Samsenwittayalai School, Bangkok, Thailand
}

\begin{abstract}
Nowadays, with the current COVID-19 pandemic, education is done in the medium of online platforms compared to the typical on-site learning. As a result, this could be a drastic change in learning environments for many. A key component for learning is motivation, which could be correlated with the happiness students experience while learning. This study aims to compare different levels of happiness and motivation to learn between online and onsite settings and to find the correlation between happiness and motivation of students while learning. The data of this study was collected through an online survey, with the participant's consent. The participants were students aged between 14-19, who have both experienced on-site learning and online learning. Participants answered 5-Likert scaled statements regarding happiness and motivation while learning in different settings. Additionally, statements regarding motivation were developed on the basis of the principle basic psychological needs which consists of three components: Autonomy, Competence, and Relatedness. The survey received 253 responses in which the data, the mean, $\mathrm{p}$-value (t-test), and the correlation value were calculated. Analysis of data showed that the mean scores of happiness and motivation of students while learning on-site were statistically higher than those of learning online at the significance level of $95 \%$. Furthermore, the results illustrated that there was a high level of correlation of happiness and motivation to learn in both learning environments.
\end{abstract}

KEYWORDS: Happiness, Motivation, On-site Learning, Online Learning, Pandemic, COVID-19

\section{INTRODUCTION}

Technology permits two major mediums of delivering the educational experience to exist. The first is the more widely accustomed traditional on-site learning. This refers to the century-old system of students attending a certain educational institution to be directly instructed by one or more educators in a classroom environment consisting of peers (Baum \& McPherson, 2019). It is typical of such constructions to include hands-on activities and face-to-face inquiries among peers, where the activities are not only highly encouraged but are most likely unavoidable (Baum \& McPherson, 2019). The second medium is the more recent adoption of electronic devices, which recently gained popularity due to the COVID-19 pandemic. It creates a learning platform that is unreliant of the need for students and instructors to be physically present. However, this online structure is more openended in nature, as courses can come at varying paces, depth, and levels of interaction (World Economic Forum, 2020). Oftentimes, courses will utilize the advantage of an online platform to present pre-recorded materials that can be accessed repeatedly at any time and anywhere (Stanford Global, 2020). Therefore, online learning puts a greater emphasis on students utilizing self-motivation to learn.

One study, conducted by Wangwongwiroj and Yasri (2021), compared students' level of perceived self-efficacy on three different modes of education: live courses, online courses, and live online courses. The study established that individual sense of efficacy was influenced mainly by the principle of mastery experience, and other concepts to consider were vicarious experience, verbal persuasion, and psychological state. It was found that the level of mastery experience, vicarious experience, and verbal persuasion was statistically highest in live courses and live online courses, while online courses failed to keep pace. Thus, it was deduced that 


\section{The Comparison of Highschool Students' Happiness between On-site and Online Learning and its Correlation with Motivation to Learn}

live courses and live online courses had a higher level of contribution to self-perceived efficacy due to the fact that both allowed students to see and consume useful examples from peers and teachers. Overall, it was concluded that the change to online courses could potentially lower the overall level of self-efficacy among students.

This study aims to explore how students' happiness in each of the learning types may correlate to their motivation to learn, where data is gathered through an online survey. Happiness was measured using statements from the Oxford Happiness survey, where happiness could be defined in different ways: participation, mental alertness, the experience of joy, emotional stability, and satisfaction in life. Research has found that it is plausible that participation in families, workplaces, and political systems will increase levels of happiness, where the main source of happiness stems from the action of establishing and sustaining social bonds. Furthermore, other processes that may have contributed include helping others and, in the case of work, the experience of flow from pursuing a strenuous task (Martin \& Barker, 2011). However, the study of happiness from participation in a school environment has not been conducted, which can be found in this study.

Scientists at UCLA have found that there was a correlation between happiness and mental alertness, measured through the release of a specific peptide, a neurotransmitter called hypocretin. This peptide greatly increased when subjects were happy but decreased when they were sad, but also elevated alertness in humans when released (Wheeler, 2013). Moreover, further support can be found through a psychology study where it was found that mind-wandering is typically associated with lower mood. The same correlation between mind wandering and lower mood was also concluded in previous studies (Franklin et. al, 2013). Moving on to the experience of joy, psychologist Rachel Fearnley described joy as a measure of contentment and happiness in everyday life that is not tied to external factors which is much less transitory than other forms of pleasure (Psychologies, 2020). Emotional stability is associated with being in control of thoughts and actions which generally lead to higher self-esteem, self-competence, and overall happiness (AMFM, 2020). Lastly, according to Daniel Gilbert, professor of Psychology at Harvard University, satisfaction in life refers to the overall contentment that an individual has with their overall life which induces a type of happiness that is stable and long-lived (Ackerman, 2021). Conclusively, this study's survey on the happiness category is aimed at these concepts.

Motivation is measured through the theory of basic psychological needs. The theory is universally accepted to be crucial not only for psychological well-being but also for autonomous motivation (Deci and Ryan, 2000). Accordingly, statements are split into three sections: autonomy, competence, and relatedness. Autonomy describes the human need for a sense of choice and personal decision. Competence, on the other hand, is defined as the ability to control outcomes and gain mastery over a specific environment. Finally, relatedness refers to the need to react with other human beings, specifically through quality and close relationships (Deci and Ryan, 2012). Thus, basic psychological needs drive human behavior and are necessary for individuals to thrive in their communal environments (Ryan et al., 1995).

\section{Methodology}

This quantitative study was carried out to investigate the correlation between the learning environment (on-site, online) and students' happiness and motivation and also aims to find the correlation between happiness and motivation of students while learning. An online survey was distributed to Thai students ages 14-19. A total of 253 responses were received. The survey consists of 22 items, each part (on-site learning, online learning) contains 11 statements for participants to rate Happiness (5 items) and Motivation (6 items). Additionally, statements regarding motivation were developed with consideration of the principle of motivation/ basic psychological needs theory (Wangwongwiroj \& Yasri, 2021) consisting of 3 components: Autonomy, Competence, and Relatedness with 2 statements. The statements were developed and verified by 3 experts with an Item-Objective Congruence (IOC) index rating, all the statements have a rating of more than 0.5 (Jusoh, Zubairi, \& Badrasawi, 2018). The acquired value of Cronbach's alpha of this survey is 0.879 showing high levels of reliability (Tavako, \& Dennickk, 2011). The respondents were informed about the purpose of this study and have acknowledged that answers to the survey will remain anonymous, participation in this study is voluntary and participants can withdraw anytime. The responses included $15.1 \%, 21.8 \%, 25.8 \%$, $23 \%, 11.1 \%$, and $3.2 \%$ of students ages $14,15,16,17,18$, and 19 year old respectively. The statements provided to the respondents were answered in a form of the 5 -Likert scale, ranging from strongly disagree (scale 1) to strongly agree (scale 5). In order to complete the survey, the participants must choose one answer out of five choices that demonstrate their level of agreement best. Then, the mean, p-value, and value of correlation are calculated. The value of correlation is rated following the scale of correlation (Mukaka, 2012). The data acquired from calculating the mean was used to prove the levels of happiness and motivation students have while learning in different environments. The $p$-value was calculated to provide statistical proof of the different levels of happiness and motivation between different learning environments. 
The Comparison of Highschool Students' Happiness between On-site and Online Learning and its Correlation with Motivation to Learn

Table I: Happiness and motivation survey items

\begin{tabular}{|l|l|}
\hline Statement & Category identified \\
\hline 1. I always participate in-class activities. & Happiness \\
\hline 2. I always feel mentally alert. & Happiness \\
\hline 3. I always experience joy. & Happiness \\
\hline 4. I always feel emotionally stable. & Happiness \\
\hline 5. I am always satisfied with my everyday life. & Happiness \\
\hline 6. I always feel comfortable to freely communicate in class. & Motivation (Autonomy) \\
\hline 7. I always feel comfortable to freely express my ideas in class. & Motivation (Autonomy) \\
\hline 8. I am always able to perform well in my favorite subjects. & Motivation (Competence) \\
\hline 9. I am always confident that I am able to get good grades. & Motivation (Competence) \\
\hline 10. I always have good relationships with my classmates. & Motivation (Relatedness) \\
\hline 11. I always have good relationships with my teachers. & Motivation (Relatedness) \\
\hline
\end{tabular}

\section{ResULTS AND DISCUSSION}

Statistical results from the survey based on Happiness and Motivation in general could be concluded from the table that the average happiness and motivation of students while learning on-site is higher than students while learning online

Table 2: Mean and p-value of on-site and online happiness and motivation

\begin{tabular}{|l|l|l|}
\hline Statement type & Mean & p-value \\
\hline On-site (Happiness) & 4.38 & \multirow{2}{*}{0.00} \\
\hline Online (Happiness) & 1.93 & \\
\hline On-site (Motivation) & 4.41 & \multirow{2}{*}{0.00} \\
\hline Online (Motivation) & 2.03 & \\
\hline
\end{tabular}

Table 3: Mean and p-value of on-site and online happiness and motivation and this category is divided into three sections following the principle of motivation, basic psychological needs (Wangwongwiroj \& Yasri, 2021): Autonomy, Competence,and Relatedness each with 2 statements.

\begin{tabular}{|l|l|l|}
\hline Statement type & Mean & p-value \\
\hline Happiness: On-site & 4.38 & \multirow{2}{*}{0.00} \\
\hline Happiness: Online & 1.93 & \\
\hline Motivation (Autonomy): On-site & 4.40 & 0.00 \\
\hline Motivation (Autonomy): Online & 1.90 & \\
\hline Motivation (Competence): On-site & 4.40 & \\
\hline
\end{tabular}


The Comparison of Highschool Students' Happiness between On-site and Online Learning and its Correlation with Motivation to Learn

\begin{tabular}{|l|l|l|}
\hline Motivation (Competence): Online & 2.20 & 0.00 \\
\hline Motivation (Relatedness): On-site & 4.50 & \multirow{2}{*}{0.00} \\
\cline { 1 - 2 } Motivation (Relatedness): Online & 2.00 & \\
\hline
\end{tabular}

The statistical results in this study shows a difference in the mean of Happiness during learning on-site to be drastically higher than learning online. Similarly, the mean of Motivation during learning on-site have a huge contrast compared to learning online in every category (Autonomy, Competence, Relatedness).There is a direct correlation between Happiness and motivation while learning, regardless of the method of education, the correlation between on-site motivation and happiness is at 0.83 and the correlation between Online motivation and happiness is at 0.88 .

Table 4: The correlation between motivation of autonomy, competence,and relatedness and happiness while learning on-site and online

\begin{tabular}{|l|l|l|}
\hline Learning environment & Statement & Happiness \\
\hline \multirow{4}{*}{ On-site } & Motivation (Autonomy) & 0.76 \\
\cline { 2 - 3 } & Motivation (Competence) & 0.72 \\
\cline { 2 - 3 } & Motivation (Relatedness) & 0.62 \\
\hline \multirow{5}{*}{ Online } & Motivation (Autonomy) & 0.79 \\
\cline { 2 - 3 } & Motivation (Competence) & 0.73 \\
\cline { 2 - 3 } & Motivation (Relatedness) & 0.80 \\
\hline
\end{tabular}

According to Table 4, The correlation between motivation of autonomy, competence, and relatedness and happiness while learning on-site is at $0.76,0.72$, and 0.62 respectively. The correlation between motivation of autonomy, competence, and relatedness and happiness while learning online is at $0.79,0.73$, and 0.80 respectively.

The data reported can be concluded that the mean score of relatedness while learning on-site was statistically the highest ( $\bar{x}=4.50)$ at the significant level of $95 \%$. On one hand, there were slight differences while learning on-site among scores of happiness $(\bar{x}=4.38)$, autonomy $(\bar{x}=4.40)$, and competence $(\bar{x}=4.40)$. On the other hand, there were also light differences while learning online ampng scores of happiness $(\bar{x}=1.93)$, relatedness $(\bar{x}=2.00)$, and competence $(\bar{x}=2.20)$. Furthermore, the lowest among the available categories was the mean score of autonomy while learning online $(\bar{x}=1.90)$.

Table 4 shows the correlation among the key variables. The most notable features of the table for the present study are the relationships between happiness and motivation (relatedness) while learning online.

The result of research showed that there is a positive and significant relationship between happiness and motivation both learning on-site and online. The result of this research is correspond with researches such as Sheikholeslami and Razavie (2005) about the positive and significant relationship between intrinsic motivation with students creativity; Sheikholeslami and Khayer (2006) about relationship between intrinsic motivation and scores of the strategies of English language learning ; Wiethead (2003) about the relationship between intrinsic motivation and achievement of students.

Students with intrinsic motivation determine goals for one and attempt toward reaching them. In fact, if they feel that they are under pressure to do interesting activities, it is likely that their motivation and internal interests would decrease. In contrast students with extrinsic motivation are likely to be determined by external factors, meaning that they are less self-determined . Their behavior is dictated by the external environment. So external factors and other individuals play a determinant role in their behavior and decisions (Bohrane, 2005).

A survey with 168 students who have had experiences being exposed to the three learning modes revealed that $72.9 \%$ still prefered a live course as it appears to attract students in respect of interaction, community, effectiveness, and enthusiasm. Those who preferred an online course (15.1\%) attributed their reasons to convenience, time flexibility, privacy and self-paced learning. 


\section{The Comparison of Highschool Students' Happiness between On-site and Online Learning and its Correlation with Motivation to Learn}

Interestingly, $12 \%$ expressed their preference towards a live online course. Although this is the smallest number, the results showed that, under this current circumstance, live online courses can serve as a promising solution as they are also perceived by the learners as a second most engaging, effective, enthusiastic, and interactive mode of learning. In contrast, online courses seem to be the least positive in all aspects, except convenience (Asawasuebsakul and Yasri, 2020).

Alexa, et al (2013) reported that this study identifies factors that increase and decrease student motivation in AS-L and explores ways to support students throughout the semester. At the beginning, middle, and end of the semester, participants completed surveys that elicited their reasons for their changes in motivation. Quantitative analyses revealed a decrease in motivation over the course of the semester and interaction between gender and student motivation. Males' motivation peaked at mid-semester, while females' motivation started at high levels and declined over the course of the semester. Qualitative analysis found that motivation increased when students enjoyed the AS-L experience, were interested in helping people, formed relationships with clients and community partners, and felt responsible to community partners. Motivation decreased due to lack of communication with community partners, lack of integration between the course and the AS-L experience, transportation issues, and difficulty with the time demands on student schedules.

Furthermore, Wangwongwiroj and Yasri (2021) reported that, this study compared students' perceived levels of $n$ be influenced by mastery experiences, verbal persuasion, vicarious experiences, and physiological states. The analysis was based upon students who had no technical difficulties to access live online courses. However, this may not be applicable to contexts where internet connection is problematic. For educational implications, the findings revealed that live online courses are proven to be the most appropriate mode of learning during the pandemic. In contrast, online courses are associated with lower levels of mastery experiences, vicarious experiences, and verbal persuasion perceived by learners; whereas live courses lower psychological states. Generally, Motivation helps people to be successful \& happy, as well as when people are motivated by happiness, they are likely to experience a fulfilling life. They will be motivated to continuously work for things that will make them happy. Motivation inspires people to progress and progression will help to make people happy, especially if they working toward things that make them happy, so motivation lead to happiness in life (Ramzan and Mahdinejad, 2013).

\section{CONCLUSIONS}

This study emphasizes investigating the statistical relationship between students' happiness and their own motivation during learning online compared to learning on-site. The responses from 253 students provide empirical evidence to support statistical links that there were strong positive correlations between happiness and motivation in both on-site and online learning, where the statistical scale in terms of happiness and motivation between learning on-site is significantly higher than learning online.Additionally, this study offers new evidence to point out a strong correlation between different learning environments and students' motivation and happiness. Furthermore, it provides status alerts correlating between happiness and motivation while learning. The results from this study can be used to improve online learning for students during the COVID-19 pandemic.

\section{REFERENCES}

1) Ackerman, C. E., MA. (2021, November 25). Life Satisfaction Theory and 4 Contributing Factors. PositivePsychology.Com. https://positivepsychology.com/life-satisfaction/

2) AMFM Mental Health Treatment Center. (2020, June 20). Ways Mental Stability Can Affect Your Happiness. A Mission For Michael. https://amfmtreatment.com/mental-stability-happiness/

3) Baum, S. B., \& McPherson, M. M. (2019, October 30). The Human Factor: The Promise \& Limits of Online Education. American Academy of Arts \& Sciences. https://www.amacad.org/publication/human-factor-promise-limits-onlineeducation

4) Deci, E. L., \& Ryan, R. M. (2012). Self-determination theory. In P. A. M. Van Lange, A. W. Kruglanski, \& E. T. Higgins (Eds.), Handbook of theories of social psychology (pp. 416-436). Sage Publications Ltd.

https://doi.org/10.4135/9781446249215.n21

5) Franklin, M., Mrazek, M., Anderson, C., Smallwood, J., Kingstone, A., \& Schooler, J. (2013). The silver lining of a mind in the clouds: Interesting musings are associated with positive mood while mind-wandering. Frontiers in Psychology, 4, 583. https://doi.org/10.3389/fpsyg.2013.00583

6) Global, S. (2020, May 13). 5 major differences between Online Learning vs Classroom Learning. Stafford Global. https://www.staffordglobal.org/articles-and-blogs/general-articles-and-blogs/5-differences-between-online-learningvs-classroom-learning/ 
The Comparison of Highschool Students' Happiness between On-site and Online Learning and its Correlation with Motivation to Learn

7) Mark, W. (2013). Is this peptide a key to happiness? (n.d.). Retrieved November 28, 2021, from https://newsroom.ucla.edu/releases/peptide-a-key-to-happiness-244002

8) Martin, B., \& Barker, C. (2020). Participation: The happiness connection. Journal of Deliberative Democracy, 7(1). https://doi.org/10.16997/jdd.120

9) Mukaka, M. M. (2012). A guide to appropriate use of correlation coefficient in medical research. Malawi medical journal, 24(3), 69-71.

10) Ryan, R. M. (1995). Psychological needs and the facilitation of integrative processes. Journal of personality, 63(3), 397427.

11) Ryan, R. M., \& Deci, E. L. (2000). Self-determination theory and the facilitation of intrinsic motivation, social development, and well-being. American psychologist, 55(1), 68.

12) Jusoh, Z., Zubairi, A. M., \& Badrasawi, K. J. (2018). Validity evident using expert judgement: A study of using item congruence involving expert judgements for evidence for validity of a reading test. Al-Shajarah: Journal of the International Institute of Islamic Thought and Civilization (ISTAC), 307-320.

13) Psychologies. (2020, February 19). 10 things to let go of if you want a happy life. https://www.psychologies.co.uk/joy-vshappiness

14) Tavakol, M., \& Dennick, R. (2011). Making sense of Cronbach's alpha. International journal of medical education, 2, 53.

15) Wangwongwiroj, T., \& Yasri, P. . (2021). The Comparison of Students' Perceived Levels of Self-Efficacy in Live, Online and Live Online Courses. International Journal on Research in STEM Education, 3(1), 47-54.

https://doi.org/10.31098/ijrse.v3i1.505

16) World Economic Forum. (n.d.).The COVID-19 pandemic has changed education forever. This is how. Retrieved November 27, 2021, from https://www.weforum.org/agenda/2020/04/coronavirus-education-global-covid19-online-digitallearning/

17) Khoshnam, A. H., \& Gendavani, A. G. (2013). The relationship between intrinsic motivation and happiness with academic achievement in high school students. International Journal of Academic Research in Business and Social Sciences, 3(11), 330. Attribution - Non Commercial 4.0 International (CC BY-NC 4.0)

(https://creativecommons.org/licenses/by-nc/4.0/), which permits remixing, adapting and building upon the work for non-commercial use, provided the original work is properly cited. 